\title{
Association between HO-1 gene promoter polymorphisms and diseases (Review)
}

\author{
LIN-LIN MA ${ }^{1 *}$, LEI SUN ${ }^{1,2^{*}}$, YU-XI WANG ${ }^{1}$, BAI-HE SUN ${ }^{1}$, YAN-FEI LI ${ }^{1}$ and YUE-LING JIN ${ }^{3}$ \\ ${ }^{1}$ School of Medical Technology, Shanghai University of Medicine \& Health Sciences, Shanghai 201318; \\ ${ }^{2}$ Department of Pathology, Yiwu Tianxiang Medical Oriental Hospital, Yiwu, Zhejiang 322000; ${ }^{3}$ Management Department of \\ Scientific Research, Shanghai Science and Technology Museum, Shanghai 200127, P.R. China
}

Received August 2, 2021; Accepted November 11, 2021

DOI: $10.3892 / \mathrm{mmr} .2021 .12545$

\begin{abstract}
Heme oxygenase-1 (HO-1) is an inducible cytoprotective enzyme that degrades heme into free iron, carbon monoxide and biliverdin, which is then rapidly converted into bilirubin. These degradation products serve an important role in the regulation of inflammation, oxidative stress and apoptosis. While the expression level of HO-1 is typically low in most cells, it may be highly expressed when induced by a variety of stimulating factors, a process that contributes to the regulation of cell homeostasis. In the 5'-non-coding region of the HO-1 gene, there are two polymorphic sites, namely the (GT)n dinucleotide and T(-413)A single nucleotide polymorphism sites, which regulate the transcriptional activity of HO-1. These polymorphisms have been shown to be closely associated with the occurrence and progression of numerous diseases, including cardiovascular, pulmonary, liver and kidney, various types of cancer and viral diseases. The present article reviews the progress that has been made in research on the association between the two types of polymorphisms and these diseases, which is expected to provide novel strategies for the diagnosis, treatment and prognosis of various diseases.
\end{abstract}

Correspondence to: Professor Yan-Fei Li, School of Medical Technology, Shanghai University of Medicine \& Health Sciences, 279 Zhouzhu Highway, Shanghai 201318, P.R. China

E-mail: liyf@sumhs.edu.cn

Professor Yue-Ling Jin, Management Department of Scientific Research, Shanghai Science and Technology Museum, 2000 Century Avenue, Shanghai 200127, P.R. China

E-mail: jinyuel@sstm.org.cn

*Contributed equally

Abbreviations: HO-1, heme oxygenase-1; CO, carbon monoxide; CHD, coronary heart disease; S, short; L, long; COPD, chronic obstructive pulmonary disease; AKI, acute kidney injury

Key words: HO-1, promoter polymorphism, (GT)n dinucleotide polymorphism, T(-413)A single nucleotide polymorphism, diseases

\section{Contents}

1. Introduction

2. Regulation of HO-1 expression

3. HO-1 promoter polymorphism

4. Association between HO-1 gene polymorphism and clinical diseases

5. Conclusions and prospects

\section{Introduction}

Heme oxygenase-1 (HO-1), also known as heat shock protein 32 , is the rate-limiting enzyme in the heme degradation pathway that degrades hemoglobin into biliverdin, free iron and carbon monoxide (CO) (1). Biliverdin is subsequently reduced to bilirubin via biliverdin reductase. Both biliverdin and bilirubin are bile pigments with antioxidant properties (2). Endogenous $\mathrm{CO}$ can act as a second messenger, thereby affecting a variety of physiological and pathological processes, including cell proliferation, inflammation, apoptosis and injury (3). As a cytoprotective enzyme, HO-1 serves an important role in maintaining cell homeostasis.

To date, three $\mathrm{HO}$ polymorphic isoenzymes have been identified, namely HO-1, HO-2 and HO-3, of which HO-1 is inducible. The HO-1-encoding gene is located on the long arm of chromosome $22 \mathrm{q} 12$ in the human body, with a total length of $6.8 \mathrm{~kb}$ (4). HO-1 is expressed in a variety of tissues, including the liver, spleen, kidney, heart, lung, brain, blood vessels, smooth muscle cells and endothelial cells, among which the highest expression is observed in the liver, spleen and kidney $(5,6)$. Under normal physiological conditions, the expression of HO-1 is relatively low in most tissues. However, under various pathophysiological stress or stimulation conditions, such as hypoxia, ultraviolet light, inflammatory mediators, heme, ischemia and other harmful stimuli, HO-1 expression is induced to protect cells against oxidative and inflammatory damage $(7,8)$. In the presence of the aforementioned stimulatory factors, the induced expression of HO-1 is primarily affected by redox-sensitive transcription factors, including nuclear factor erythroid 2-related factor 2 (Nrf2), activator protein 1 (AP1), hypoxia-inducible factor (HIF) and BTB and CNC homology 1 (Bach1) (9). In addition, a 
large number of epidemiological genetic studies have shown that the expression of HO-1 is regulated by genetic polymorphisms in the promoter of its gene, which might be associated with a variety of diseases, such as coronary atherosclerosis, rheumatoid arthritis and viral diseases (10-13).

The present review focuses on the clinical evidence that HO-1 gene polymorphisms are associated with the incidence and outcome of different diseases. To further understand this association, a brief discussion of the regulation of $\mathrm{HO}-1$-induced expression mediated by transcription factors is included.

\section{Regulation of HO-1 expression}

As a stress-induced cytoprotective enzyme, the investigation of the molecular mechanism underlying HO-1 regulation began with studies on how various stress stimulation conditions, including stress, hypoxia and small-molecule inducers, could influence the activity of the enzyme. Under these stress conditions, the expression of HO-1 is primarily regulated by redox-sensitive transcription factors, including Nrf2, AP1, HIF and Bach1. The present review discusses the mechanisms through which each of these factors regulate HO-1.

$\mathrm{Nrf} 2$ is considered to be the primary transcription factor that regulates the expression of HO-1 (14). Under basic conditions, Nrf2 can form a protein complex with Kelch-like ECH-associated protein 1 (KEAP1) in the cytoplasm, which inhibits the activity of Nrf2 via proteasome-mediated degradation of $\operatorname{Nrf} 2(15,16)$. When cells are exposed to chemical or physical stimuli, Nrf2 separates from KEAP1 and transfers to the nucleus, where it binds to MAF bZIP transcription factor (Maf). The Nrf2/Maf heterodimers bind the antioxidant response element (ARE), leading to the transcriptional activation of antioxidant genes, including the HO-1 gene $(17,18)$. Bach1, a heme sensor, acts as a major transcriptional repressor of HO-1 expression. Bach1 impairs the DNA-binding activity of Nrf2 by competing with Nrf2 for binding to the AREs of numerous antioxidant genes under basal conditions. High levels of heme in cells can cause Bach1 to dissociate from AREs, leading to nuclear export and subsequent proteasome-mediated degradation of Bach1. Under these circumstances, transcriptional expression of HO-1 occurs $(19,20)$. In general, in response to various stress stimuli, the feedback loop formed by Nrf2, KEAP1 and Bach1 has a pivotal role in regulating the expression of $\mathrm{HO}-1$.

Other transcriptional factors have been shown to be involved in the regulation of HO-1 expression, including HIF-1, AP1 and $\mathrm{NF}-\kappa \mathrm{B}(21,22)$. Similarly to Nrf2, these factors can combine with the cis-regulatory element of the HO-1 gene, resulting in an increase in HO-1 expression (21). HIF-1, a redox-responsive transcription factor, induces HO-1 expression in different cell types under hypoxic conditions (23-26). However, a specific mutant of HIF-1 lost its DNA-binding activity, which resulted in inhibition of HO-1 expression (27). Mechanistic studies have shown that HIF-1 $\alpha / \mathrm{HIF}-1 \beta$ heterodimers are necessary for hypoxia-induced HO-1 expression, since hypoxia induces the expression of HIF-1 $\alpha$, which binds to specific DNA sequences dependent on HIF-1 $\beta$ (27). AP1 transcriptional factor is generated by dimers of the Jun and Fos family proteins. AP1 is able to bind to tetradecanoylphorbol-13-acetate-responsive elements of the HO-1 gene promoter $(28,29)$, subsequently leading to the upregulation of HO-1 expression, which has been demonstrated by functional studies and sequence analysis of the promoter (21,30-32). Similarly to AP1, the NF- $\kappa$ B family of transcription factors are dimerization complex factors formed by $\mathrm{REL}$ proto-oncogene, $\mathrm{NF}-\kappa \mathrm{B}$ subunit family proteins. $\mathrm{NF}-\kappa \mathrm{B}$ homodimers comprising p52 and p50 are transcription repressors, whereas $\mathrm{NF}-\kappa \mathrm{B}$ heterodimers formed by $\mathrm{p} 65$ and p50 act primarily as transcription activators $(21,33)$. AP1 and $\mathrm{NF}-\kappa \mathrm{B}$ have been shown to regulate $\mathrm{HO}-1$ expression primarily in immune cells, thereby fulfilling an important role in protecting against inflammation-mediated damage, including that mediated by reactive oxygen species (34).

In addition to the direct regulation mediated by a range of transcription activators, a large number of HO-1 inducers are also able to indirectly activate the expression of the protein through acting on the protein kinase signaling pathway. Numerous plant-derived polyphenols have been found to induce HO-1 gene expression by activating the MAPK, PI3K/AKT and AMP-activated protein kinase (AMPK) signaling pathways (35-37). For example, salvianolic acid A, a plant-derived polyphenol that has been widely studied, provides significant protection in several cell types following exposure to different stimuli by activating the PI3K/Akt/mTOR complex 1 or MAPK ERK/p38 signaling pathways (38-40). Quercetin, another polyphenol antioxidant, activates the MAPK signaling pathway, thereby inducing the expression of HO-1, which provides protection against apoptosis and inflammation $(41,42)$. Additionally, plant-derived polyphenols have been reported to show antioxidative stress and anti-inflammatory properties via AMPK-dependent induction of HO-1 $(43,44)$. The precise mechanism by which the protein kinase signaling pathway induces the expression of $\mathrm{HO}-1$ involves the cross-talk of transcription factors, including Nrf2, AP1 and HIF-1, and has been previously reviewed in detail $(21,34)$. In general, the induced expression of HO-1 is an adaptive strategy that enables cells to achieve self-protection under stress conditions. However, a variety of genetic epidemiological studies have shown that there are two important genetic polymorphisms in the promoter region of the HO-1 gene (45-47). These polymorphisms determine the expression level of HO-1 and affect several diseases, such as cardiovascular, pulmonary, liver, renal, cancer and viral diseases.

\section{HO-1 promoter polymorphism}

HO-1 gene polymorphisms are primarily based on two sites: The (GT)n double nucleotide polymorphism (also called microsatellite polymorphism) and the T(-413)A single nucleotide polymorphism (SNP), both of which can regulate HO-1 gene transcription under specific conditions (45). These two polymorphic sites on the HO-1 gene promoter are shown in Fig. 1.

(GT)n double nucleotide polymorphism. Of the two polymorphism sites found in the HO-1 promoter region, the (GT) $\mathrm{n}$ dinucleotide repeat polymorphism (rs3074372) occurs more commonly. The number of (GT)n repeats ranges from 12-45 repeats (48), and the distribution of (GT)n repeats is bimodal, with alleles of $\sim 23$ and 30 repeat lengths $(5,12,48-52)$. 
Two polymorphic sites of $\mathrm{HO}-1$

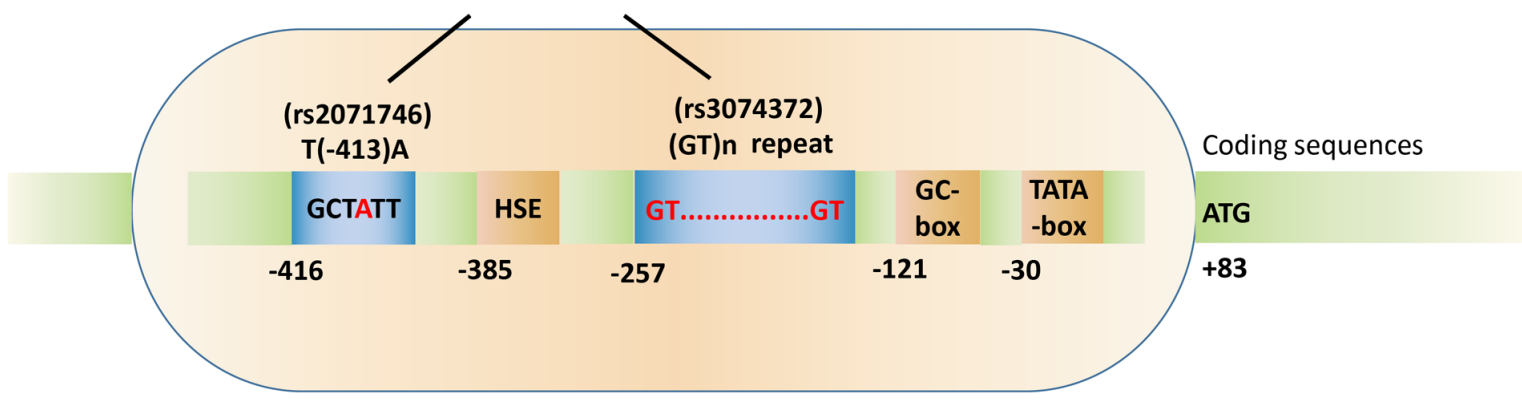

Figure 1. Polymorphic sites on HO-1 gene promoter. The two polymorphic sites including the (GT)n dinucleotide repeat polymorphism (rs3074372) and the $\mathrm{T}(-413)$ A single nucleotide polymorphism (rs2071746) in the 5'-flanking region of the heme oxygenase-1. The number of (GT)n repeats ranges from 12-45. HO-1, heme oxygenase-1; HSE, heat shock element.

According to this genetic distribution in humans and the effect of GTn repeats on the transcriptional activity of HO-1, short (S) alleles have been defined as having $<25$ GTn repeats, whereas those with $\geq 25$ repeats were defined as long (L) alleles $(49,53)$. Alternatively, other studies have used a different classification method: S alleles have been denoted by $<27$ GT, middle alleles (M) as 27-32 GT and L alleles as $\geq 33$ GT $(11,54)$. The biological function generated through the use of either classification system should be consistent, taking into account the (GT)n distribution frequency (5).

Through the use of the luciferase reporter gene system in vitro, previous studies have confirmed that $\mathrm{S}$ alleles are associated with a higher transcriptional activity of HO-1 compared with L alleles $(51,52)$. Consistent with this, genetic epidemiological studies have shown that subjects with $\mathrm{S}$ alleles have higher levels of HO-1 mRNA compared with subjects with $\mathrm{L}$ alleles $(12,13)$. Moreover, when lymphocytes isolated from humans were exposed to $\mathrm{H}_{2} \mathrm{O}_{2}$ stimulation in vitro, the HO-1 expression level in cells with $\mathrm{S}$ alleles was found to be higher compared with that of cells with L alleles. Functionally, lymphocytes with $\mathrm{S}$ alleles exhibit a stronger antiapoptotic ability (11). On the other hand, L (GT)n repeats have been demonstrated to be associated with a higher susceptibility to the development of numerous diseases, such as hypertension, atherosclerosis, acute kidney injury, breast cancer and pancreatitis. Clinical studies have shown that the (GT)n repeat length of the HO-1 promoter is correlated with the progression of a variety of diseases, such as hypertension, atherosclerosis, and acute kidney injury (55-57).

T(-413)A SNP. T(-413)A SNP (rs2071746), another HO-1 promoter polymorphism, was detected by reverse transcription-quantitative PCR. Yamada et al (52) transfected plasmids containing different HO-1 gene promoters into bovine aortic endothelial cells to detect functional differences caused by SNPs. The results obtained showed that cells containing the A(-413)-(GT) $)_{30}$ allele were able to significantly enhance the biological activity of HO-1. Several studies have subsequently confirmed that the A allele is also associated with a high transcription level of $\mathrm{HO}-1$, which correlates closely with the occurrence and progression of certain human diseases, including cardiovascular, and liver diseases (58-60). A previous study reported that the AA genotype of T(-413) A could significantly reduce the occurrence of myocardial infarction and angina pectoris (61). In addition, the survival rate of transplanted livers was shown to be significantly higher following liver transplantation from donors who carried the A allele (62).

Population characteristics of HO-1 gene promoter polymorphisms. According to a study of HO-1 gene promoter polymorphism in Caucasian and East Asian populations, the distribution of (GT)n alleles showed a bimodal pattern with $(\mathrm{GT})_{23}$ and $(\mathrm{GT})_{30}$ being the two most common alleles in the two groups $(50,51)$. However, the distribution of (GT)n alleles showed a trimodal pattern with peaks at $(\mathrm{GT})_{23},(\mathrm{GT})_{30}$ and $(\mathrm{GT})_{39}$ in African-American populations (50). Compared with Caucasian populations, meta-analysis showed that East Asian populations had more $\mathrm{S}$ alleles and fewer L alleles (58). (GT)n polymorphism includes three genotypes, namely SS, SL and LL. East Asian populations showed higher SS frequencies, ranging from 15 to $25 \%$, whereas Caucasian populations displayed SS frequencies ranging from 6 to $17 \%$ (58). The SS genotype was associated with a lower incidence of chronic diseases, such as coronary heart disease and rheumatoid arthritis $(12,58)$. The incidence of rheumatoid arthritis in East Asian populations is lower than that in Caucasian populations, which might be related to the higher SS genotype in East Asians. In addition, a recent study showed that Caucasian American populations have a higher SS allele frequency compared with African American populations, which might be the cause of higher neurocognitive impairment caused by human immunodeficiency virus (HIV) infection in African American populations (50). Similarly, the T(-413)A SNP polymorphism genotype also contains three genotypes, namely AA, AT and TT. These genotypes also differs between Caucasian and East Asian populations. Meta-analysis showed that East Asian populations had a lower AA genotype $(\sim 22 \%)$ compared with Caucasian populations $(\sim 35 \%)$. People with the AA genotype displayed a lower risk of coronary heart disease (58).

Mechanism of promoter polymorphisms regulating $\mathrm{HO}-1$ expression. To date, the mechanism through which the T(-413) A and (GT)n gene polymorphisms regulate the expression of HO-1 has not been elucidated. A potential explanation may be that (GT)n microsatellite repeats tend to form a Z-DNA conformation, such as a left-handed double-helix structure (63). The Z-DNA conformation only occurs rarely in the 
genome, although its incidence does increase under certain conditions, such as the presence of a purine/pyrimidine-alternating sequence, DNA supercoiling and a high concentration of salt and certain cations $(5,64)$. During the transcription process, the local Z-DNA conformation reduces the transcription activity of DNA. Therefore, the L (GT)n microsatellite repeats in the promoter tend to form a Z-DNA conformation, which consequently reduces the transcriptional activity of HO-1. In addition, a previous study showed that the T(-413)A and (GT)n polymorphisms may be involved in the splicing and translation of the HO-1 transcript (65). An extra exon (Exon1a) was identified for the first time in the 5'-untranslated region (5'-UTR) of HO-1. Moreover, the T(-413)A and (GT)n loci are located between Exon1a and Exon1. T(-413)A and (GT) $\mathrm{n}$ are located in the primary transcripts of HO-1 as alternative intronic or exonic elements. Rapid amplification of cDNA ends and luciferase reporter assays were subsequently used to confirm that T(-413)A and (GT)n are involved in 5'-UTR alternative splicing of the HO-1 primary transcript, which may result in translational control of HO-1 through regulating mRNA stability and translational efficiency (65). Moreover, expression of Exon 1a induced by hemin in hepatoma HepG2 cells is shown to decrease mature HO-1 mRNA isoform translation, which might explain the previous finding that human HO-1 mRNA and protein levels fail to correlate (66).

\section{Association between HO-1 gene polymorphism and clin- ical diseases}

As a cytoprotective enzyme, the intracellular expression level of HO-1 is influenced by the (GT)n dinucleotide polymorphism and T(-413)A SNP in its promoter region. Several studies have shown that these two polymorphisms affect the occurrence and progression of a variety of diseases, including liver and kidney, lung, cardiovascular, cancer and viral diseases $(48,52,55-58,67)$. The association between two HO-1 promoter polymorphisms and diseases are summarized in Table I.

Cardiovascular disease. HO-1 is a protective factor for cardiovascular diseases (68). Previous studies have shown that the level of serum bilirubin, a downstream product of HO-1, is negatively correlated with the occurrence of coronary heart disease (CHD), and lower levels of serum bilirubin increase the risk of CHD. Through a correlation analysis, Zhang et al (58) demonstrated that the HO-1 (GT)n repeat length polymorphism and T(-413)A SNP were both associated with a risk of CHD following percutaneous coronary intervention. Patients with the S allele of HO-1 (GT)n had a reduced risk of restenosis compared with those with the L allele of HO-1 (GT)n. Similarly, the HO-1 A allele of T(-413)A was associated with a reduced risk of $\mathrm{CHD}$. Consistent with the aforementioned results, Liang et al (69) showed that the HO-1 promoter (GT)n repeat sequence in patients with $\mathrm{CHD}$ with a reduced ejection fraction was longer compared with that in patients with CHD with moderate ejection fraction.

Ono et al (59) demonstrated that the HO-1 AA genotype is associated with an increased incidence of hypertension in a female population. Wenzel et al (55) reported that the individuals carrying the HO-1 L allele had an increased risk for the prevalence of arterial hypertension and higher overall mortality. In line with this, another study demonstrated that the HO-1 S allele may serve a protective role against environmental stressors in blood pressure regulation and cardiovascular mortality risk in hypertensive individuals (70). Therefore, the (GT)n repeat or SNP polymorphisms may be used as molecular markers for screening individuals who are at risk of hypertension.

Atherosclerosis is an inflammatory disease (71). As an anti-inflammatory protein, $\mathrm{HO}-1$ has been confirmed to have a protective effect on blood vessels and is able to inhibit the formation of atherosclerotic lesions (72-74) and thrombosis (75). Liang et al (76) also found that the HO-1 promoter (GT)n repeat sequence was longer in patients with microvascular angina compared with that in healthy controls. Similarly, Pechlaner et al (56) demonstrated that there is a strong correlation between the HO- $(\mathrm{GT}) \mathrm{n}$ repeat polymorphism and cardiovascular disease risk in subjects for whom the number of (GT)n repeats was $\geq 32$. Taken together, these studies provided some indicators for how atherosclerosis may be accelerated and antioxidant defenses decreased in high-risk vascular groups.

In conclusion, individuals carrying the L allele of $\mathrm{HO}-1$ (GT)n were shown to have an increased risk of CHD, hypertension and atherosclerosis, whereas the A allele of T(-413)A in the HO-1 gene promoter is associated with a lower risk of CHD, but an increased risk of hypertension. However, these controversial conclusions might have resulted from the limited number of subjects and different populations included in the CHD studies, thus these limitations also need be taken into consideration.

Pulmonary disease. The induction of HO-1 expression is considered to be an important protective mechanism involved in acute and chronic lung diseases, and HO-1 is an important enzymes that exerts antioxidant protective effects in the lung (77). HO-1 gene polymorphism is closely associated with chronic obstructive pulmonary disease (COPD) $(52,78,79)$.

A previous study confirmed that insufficient or inhibited levels of HO-1 expression are an important internal factor for inducing the occurrence of COPD (80). Zhang et al (81) found that $\mathrm{HO}-1$ exerts a protective function on the lungs, and the number of GT repeats was shown to influence the effects of oral N-acetylcysteine treatment. Patients with L (GT)n alleles were shown to have a much higher rate of deterioration compared with patients that lacked the L alleles. From this study, it may be concluded that HO-1 gene polymorphism has an important role in COPD. Yamada et al (52), Du et al (78) and Zhou et al (79) also demonstrated that the L (GT)n allele frequency in patients with COPD was significantly higher compared with that in the control group.

Liver disease. HO-1 has also been shown to protect allografts against ischemia/reperfusion and immune rejection. By studying 60 patients with allogeneic orthotopic liver transplantation and their accompanying donors, Zhang et al (82) found that donor-derived HO-1 gene promoter polymorphism exerted a protective effect on allograft function following orthotopic transplantation. A short (GT)n sequence ( $\mathrm{n}<25$ repeats) leads to increased HO-1 transcriptional activity, and a series of 
Table I. Association between two HO-1 promoter polymorphisms and a variety of diseases.

A, (GT)n dinucleotide polymorphism

Disease

Coronary heart disease

Hypertension

Atherosclerosis

Pulmonary disease

Chronic obstructive pulmonary disease

Liver disease

Liver transplantation

Renal disease

Acute kidney injury

Cancer

Pancreatic cancer, melanoma

Acute lymphoblastic leukemia

Breast cancer, esophageal squamous cell carcinoma and laryngeal squamous cell carcinoma Gastric cancer and lung adenocarcinoma

Viral disease

HIV

$\mathrm{HCV}$

Other disease

Neonatal hyperbilirubin

Rheumatoid arthritis

Pancreatitis
S (GT)n repeats reduce the risk of coronary heart disease

$\mathrm{P}<0.05$ or restenosis

Carriers with the L (GT)n allele have an increased risk of

$\mathrm{P}<0.05$ hypertension, whereas the S (GT)n allele may play a protective role

Subjects with (GT)n repeats $\geq 32$ display an increased

$\mathrm{P}<0.01$ risk of cardiovascular disease and enhanced atherosclerosis progression

$\mathrm{L}$ (GT)n allele is a high risk factor for chronic obstructive $\quad \mathrm{P}<0.01$ pulmonary disease

$\mathrm{S}(\mathrm{GT}) \mathrm{n}$ sequence $(\mathrm{n}<25)$ is beneficial to the

$\mathrm{P}<0.05$ functional improvement and survival of allografts

$\mathrm{P}<0.05$

Carrying the L (GT)n allele increases the risk of acute kidney injury after heart surgery, whereas carrying $\mathrm{S}$ (GT)n allele increases the risk of acute kidney injury in patients with sepsis

The S (GT)n allele sequence is associated with an increased risk and lesion of pancreatic cancer and melanoma

$\mathrm{P}<0.001$

(pancreatic cancer) or

$\mathrm{P}<0.05$

(melanoma)

$\mathrm{P}<0.05$

resistance and chemo-induced neutropenia

L (GT)n repeats are associated with a higher risk of

$\mathrm{P}<0.05$ these type of cancer

The effect of HO-1 promoter polymorphism on

N/A cancer may depend on a variety of factors, including tumor type, subject ethnicity and other factors

S (GT)n allele inhibits neuroimmune activation,

$\mathrm{P}<0.05$ HIV-associated neuroinflammation and neurocognitive deficits

$\mathrm{S}$ (GT)n allele decreases the infection titer of $\mathrm{HCV}$

$\mathrm{P}>0.05$

S (GT)n repeat gene promoter results in a higher

$\mathrm{P}<0.05$ risk of neonatal hyperbilirubinemia

$\mathrm{S}$ (GT)n allele reduces the risk of rheumatoid

$\mathrm{P}<0.05$ arthritis and prevents the development of joint injury

HO- 1 containing LL allele doubles the risk of

$\mathrm{P}<0.05$ pancreatic necrosis in patients with acute pancreatitis 
Table I. Continued.

B, T(-413)A single nucleotide polymorphism

\begin{tabular}{|c|c|c|c|}
\hline Disease & Polymorphism & P-value & (Refs.) \\
\hline \multicolumn{4}{|l|}{ Cardiovascular disease } \\
\hline Coronary heart disease & The A allele reduces the risk of coronary heart disease & $\mathrm{P}<0.05$ & $(58)$ \\
\hline Hypertension & $\begin{array}{l}\text { AA genotype increases the incidence of hypertension in a } \\
\text { female population }\end{array}$ & $\mathrm{P}<0.01$ & $(59)$ \\
\hline \multicolumn{4}{|l|}{ Liver disease } \\
\hline Liver transplantation & $\begin{array}{l}\text { Patients carrying the } \mathrm{T} \text { allele are more likely to develop } \\
\text { esophageal varices compared with those carrying the A allele }\end{array}$ & $\mathrm{P}<0.001$ & $(60)$ \\
\hline \multicolumn{4}{|l|}{ Other disease } \\
\hline Type II diabetes & $\begin{array}{l}\text { Patients with the TT genotype are more prone to developing } \\
\text { proteinuria }\end{array}$ & $\mathrm{P}<0.05$ & $(106)$ \\
\hline Ischemic heart disease & $\begin{array}{l}\text { The AA genotype of HO- } 1 \text { reduces the incidence of ischemic } \\
\text { heart disease }\end{array}$ & $\mathrm{P}<0.05$ & $(61)$ \\
\hline
\end{tabular}

HO-1, heme oxygenase-1; L, long; S, short; HIV, human immunodeficiency virus; HCV, hepatitis C virus.

transplantation models have demonstrated that HO-1 upregulation is beneficial to the functional improvement and survival of the allograft (82-85). In addition, studies have shown that patients with liver cirrhosis who carry the HO-1 $\mathrm{T}$ allele are more likely to develop esophageal varices than those with liver cirrhosis who carry the A allele. Therefore, the $\mathrm{T}$ allele of the HO-1 gene SNP is a risk factor for esophageal varices in patients with cirrhosis (60).

Renal disease. Acute kidney injury (AKI) refers to a multifactorial clinical syndrome caused by a variety of diseases, such as hypovolemia, diabetes, heart or lung disease (86). Leaf et al (57) demonstrated that repeated HO-1 polymorphism is associated with the development of AKI after cardiac surgery in adults, and carrying the HO-1 L (GT)n sequence ( $n>27$ repeats) increases the risk of AKI after cardiac surgery. Hemolysis may be the primary cause of AKI, but the factors associated with cardiac surgery are complex and varied. The most plausible mechanism that has been proposed to date is that the expression of HO-1 is reduced in patients with $\mathrm{L}(\mathrm{GT}) \mathrm{n}$ repeats, resulting in a decrease in the decomposition of heme. Therefore, patients with reduced HO-1 expression caused by L (GT)n repeats may have increased susceptibility to heme-related AKI during cardiac surgery.

In a different study, Vilander et al (87) classified the HO-1 (GT)n repeat sequence in 300 patients with severe AKI sepsis and 353 patients without AKI sepsis. The alleles were classified according to the number of replicates. The short sequence $\mathrm{S}$ was defined as $<27$ repeats, the long sequence $\mathrm{L}$ was defined as $\geq 27$ repeats and the very long sequence (L2) was defined as $\geq 34$ repeats. Patients with at least one L2 sequence had lower plasma HO-1 concentrations compared with those without the L2 sequence. Patients with the S allele were found to be at an increased risk for AKI, and the adjusted odds ratio for each $\mathrm{S}$ allele was 1.3 in the additive genetic model. The conclusions of the aforementioned two studies are different as the susceptibility factors of the study populations were different. In the study conducted by Leaf et al, patients underwent cardiopulmonary bypass surgery, whereas all patients were critically ill with sepsis in the study conducted by Vilander et al. In addition, urination criteria were not included in the study by Leaf et al, but patients with mild AKI were excluded in the study by Vilander et al. In conclusion, it is necessary to distinguish the different phenotypes of AKI clinical syndromes when conducting pathophysiological studies on patients with AKI.

Cancer. Increasing evidence on the association between HO-1 gene promoter polymorphism and cancer has been reported. Previous studies have shown that S (GT)n repeats in the HO-1 promoter lead to higher transcriptional activity, which leads to an increased risk of pancreatic cancer and melanoma $(88,89)$. In pancreatic cancer studies, patients with HO-1 S (GT)n repeats developed cancer more rapidly and were more likely to experience recurrence. This finding was consistent with the fact that HO-1 expression in pancreatic tumors was higher compared with that in healthy tissues, and that HO-1 overexpression has been shown to accelerate the growth, angiogenesis and metastasis of pancreatic tumors $(90,91)$. In pediatric patients with acute lymphoblastic leukemia, patients with HO-1 S (GT) $n$ repeats were associated with chemotherapy resistance and chemo-induced neutropenia (92). In other studies, L (GT)n repeats in the promoter of the HO-1 gene have been reported to be associated with a higher risk of breast cancer, esophageal squamous cell carcinoma and laryngeal squamous cell carcinoma (67,93-95).

However, the effects of HO-1 promoter polymorphism in certain types of cancer have given rise to inconsistent results. For example, Lo et al (96) studied 183 patients with gastric cancer and 250 control patients in the Taiwan area. The results demonstrated that the L (GT)n repeat of the HO-1 gene promoter was associated with a high frequency of gastric 
cancer, and that the $\mathrm{M}(\mathrm{GT}) \mathrm{n}$ repeat may have a protective effect on gastric adenocarcinoma with a low frequency of lymphatic vascular invasion. However, Sawa et al (97) found that, in the female Japanese population, HO-1 S (GT)n repeats were associated with a risk of gastric cancer. This difference in the reported results may have been due to environmental factors and living habits. In addition, for lung adenocarcinoma, male smokers with the $\mathrm{L}$ allele had a significantly increased risk of lung adenocarcinoma compared with those with the non-L allele. In female non-smokers, $\mathrm{L}$ allele carriers did not differ between patients and controls (98). For sporadic colorectal cancer, studies have shown no association between HO-1 promoter (GT)n repeat polymorphism/T(-413)A SNP and the risk of disease (99). Taken together, these findings suggested that the effect of HO-1 gene promoter polymorphism on cancer may depend on a variety of factors, including tumor type and subject ethnicity (100).

Viral diseases. Studies have shown that gene polymorphisms in the HO-1 promoter region are associated with the occurrence and progression of viral infectious diseases. Gill et al (48) demonstrated that individual HO-1 (GT)n allele repeat length polymorphisms have a unique modifying effect on the risk of $\mathrm{HIV}$-induced central nervous system neuroinflammation and associated neuropathy. The HO-1 S (GT)n allele increases HO-1 promoter activity and exerts a neuroprotective function through inhibiting neuroimmune activation. Similarly, previous studies have shown that the HO-1 S (GT)n allele sequence in African American populations reduces HIV-associated neuroinflammation and limits HIV-induced neurocognitive deficits $(10,50)$. Therefore, therapeutic strategies that induce HO-1 expression should be able to reduce HIV-associated central nervous system inflammation and reduce the risk of HIV neurological disease development.

Kah et al (101) showed that inoculating mice with human hepatocytes containing the HO-1 S (GT)n allele led to a decrease in the infection titer of hepatitis $\mathrm{C}$ virus (HCV) compared with mice inoculated with the HO-1 L (GT)n allele. Therefore, HO-1-mediated HCV inhibition is (GT)n polymorphism-dependent. In addition, it has been suggested that HO-1 promoter polymorphism may influence coronavirus COVID-19 disease severity, such as acute lung injury and thromboembolism. Therefore, the repeat length of the HO-1 (GT)n allele in patients with severe COVID-19 should be investigated (102).

Other diseases. HO-1 gene promoter polymorphism has also been reported to be associated with neonatal hyperbilirubinemia (103), rheumatoid arthritis $(12,104)$, pancreatitis (105), type II diabetes mellitus (106), heart disease (107) and other diseases to varying degrees. HO-1 carrying an S (GT)n repeat gene promoter was found to be associated with a higher risk of neonatal hyperbilirubinemia (103). By contrast, carrying the $\mathrm{S}$ (GT)n microsatellite allele was found to reduce the risk of rheumatoid arthritis and prevent the development of joint injury, whereas carrying the L (GT)n microsatellite allele led to an increase in the susceptibility to rheumatoid arthritis and promoted the development of joint injury $(12,104)$. For pancreatitis, the results of logistic regression analysis revealed that HO-1 containing the L (GT)n allele doubled the risk of pancreatic necrosis in patients with acute pancreatitis (105). However, in patients undergoing heart transplantation, (GT) $\mathrm{n}$ polymorphism was not found to be associated with heart failure or patient survival. The researchers assumed that lower HO-1 activity in patients with L (GT)n alleles might be compensated by other protective genes or enzymes (107). In addition, in a retrospective analysis of patients with type II diabetes, HO-1 T(-413)A SNP was significantly associated with the prevalence of low proteinuria, and patients with the TT genotype were more prone to develop proteinuria. Furthermore, in vitro experiments revealed that the promoter activity of HO-1 containing the A allele was higher than that of T allele (106). The AA genotype of HO-1 for T(-413)A SNP polymorphism was also found to reduce the incidence of ischemic heart disease, which might be associated with the high expression level of HO-1 (61).

\section{Conclusions and prospects}

As a stress-induced cytoprotective enzyme, HO-1 expression is regulated by a complex network, including transcription factors, cytoplasmic signaling pathways, post-translational modifications and genetic polymorphisms. The research of HO-1 induced expression primarily focuses on transcription factors. To treat a variety of diseases related to inflammation and immune regulation, screening small molecule HO-1 inducers that target transcription factors is the most commonly used method $(108,109)$. However, this attempt at translational research was not successful and encountered great challenges. In addition to toxicity and bioavailability issues, HO-1 gene polymorphism in the population may also be an important reason for the difficulty of this translational study. Therefore, if the HO-1 gene polymorphism is added as a biomarker in clinical trials, it may improve the success rate of translational research. The current challenge is that the clinical results of the correlation between HO-1 gene polymorphism and disease are still controversial, especially due to the small sample sizes and inconsistent definition standards. On the other hand, the molecular mechanism underlying HO-1 polymorphism-mediated effects on $\mathrm{HO}-1$ gene expression under disease conditions has not been fully revealed, which limits our understanding of the correlation between HO-1 gene polymorphisms and different diseases. Through the method of in vitro transient transfection, the relationship between (GT)n repeats length and HO-1 expression level has been established at the cellular level; however, the research of (GT)n repeat length effects on HO-1 expression at the animal level has not yet been reported. With the emergence of CRISPR technology, it is possible to construct HO-1 gene polymorphism transgenic mice. Future research should focus on exploring the molecular mechanisms by which HO-1 gene polymorphism and transcription factors coregulate HO-1 expression and affect disease using transgenic mouse systems. These investigations will provide further support for the development of targeted HO-1 reagents in different diseases.

\section{Acknowledgements}

Not applicable. 


\section{Funding}

The present study was supported by the National Natural Science Foundation of China (grant no. 81902052).

\section{Availability of data and materials}

Not applicable.

\section{Authors' contributions}

LLM and LS wrote and prepared the final version of the manuscript. YXW and BHS contributed to revising the manuscript. YFL and YLJ conceptualized the idea of the review. All authors read and approved the final manuscript. Data authentication is not applicable.

\section{Ethics approval and consent to participate}

Not applicable.

\section{Patient consent for publication}

Not applicable.

\section{Competing interests}

The authors declare that they have no competing interests.

\section{References}

1. Gozzelino R, Jeney V and Soares MP: Mechanisms of cell protection by heme oxygenase-1. Annu Rev Pharmacol Toxicol 50: 323-354, 2010.

2. Wagener FA, Volk HD, Willis D, Abraham NG, Soares MP, Adema GJ and Figdor CG: Different faces of the heme-heme oxygenase system in inflammation. Pharmacol Rev 55: 551-571, 2003.

3. Kim HP, Ryter SW and Choi AM: CO as a cellular signaling molecule. Annu Rev Pharmacol Toxicol 46: 411-449, 2006.

4. Calabrese V, Butterfield DA, Scapagnini G, Stella AG and Maines MD: Redox regulation of heat shock protein expression by signaling involving nitric oxide and carbon monoxide: Relevance to brain aging, neurodegenerative disorders, and longevity. Antioxid Redox Signal 8: 444-477, 2006.

5. Exner M, Minar E, Wagner O and Schillinger M: The role of heme oxygenase-1 promoter polymorphisms in human disease. Free Radic Biol Med 37: 1097-1104, 2004.

6. Linnenbaum M, Busker M, Kraehling JR and Behrends S: Heme oxygenase isoforms differ in their subcellular trafficking during hypoxia and are differentially modulated by cytochrome P450 reductase. PLoS One 7: e35483, 2012.

7. Shibahara S: The heme oxygenase dilemma in cellular homeostasis: New insights for the feedback regulation of heme catabolism. Tohoku J Exp Med 200: 167-186, 2003.

8. Zhou J, Terluk MR, Basso L, Mishra UR, Orchard PJ, Cloyd JC, Schröder H and Kartha RV: N-acetylcysteine provides cytoprotection in murine oligodendrocytes through heme oxygenase-1 activity. Biomedicines 8: 240, 2020.

9. Jazwa A and Cuadrado A: Targeting heme oxygenase-1 for neuroprotection and neuroinflammation in neurodegenerative diseases. Curr Drug Targets 11: 1517-1531, 2010.

10. Seu L, Burt TD, Witte JS, Martin JN, Deeks SG and McCune JM: Variations in the heme oxygenase-1 microsatellite polymorphism are associated with plasma CD14 and viral load in HIV-infected African-Americans. Genes Immun 13: 258-267, 2012.

11. Hirai H, Kubo H, Yamaya M, Nakayama K, Numasaki M, Kobayashi S, Suzuki S, Shibahara S and Sasaki H: Microsatellite polymorphism in heme oxygenase-1 gene promoter is associated with susceptibility to oxidant-induced apoptosis in lymphoblastoid cell lines. Blood 102: 1619-1621, 2003.
12. Rueda B, Oliver J, Robledo G, López-Nevot MA, Balsa A, Pascual-Salcedo D, González-Gay MA, González-Escribano MF and Martín J: HO-1 promoter polymorphism associated with rheumatoid arthritis. Arthritis Rheum 56: 3953-3958, 2007.

13. Brydun A, Watari Y, Yamamoto Y, Okuhara K, Teragawa H, Kono F, Chayama K, Oshima T and Ozono R: Reduced expression of heme oxygenase-1 in patients with coronary atherosclerosis. Hypertens Res 30: 341-348, 2007.

14. Loboda A, Damulewicz M, Pyza E, Jozkowicz A and Dulak J: Role of Nrf2/HO-1 system in development, oxidative stress response and diseases: An evolutionarily conserved mechanism. Cell Mol Life Sci 73: 3221-3247, 2016.

15. Zhang DD: Mechanistic studies of the Nrf2-Keap1 signaling pathway. Drug Metab Rev 38: 769-789, 2006.

16. Jaramillo MC and Zhang DD: The emerging role of the Nrf2-Keap1 signaling pathway in cancer. Genes Dev 27: 2179-2191, 2013.

17. Motohashi H, Katsuoka F, Engel JD and Yamamoto M: Small Maf proteins serve as transcriptional cofactors for keratinocyte differentiation in the Keap1-Nrf2 regulatory pathway. Proc Natl Acad Sci USA 101: 6379-6384, 2004.

18. Itoh K, Chiba T, Takahashi S, Ishii T, Igarashi K, Katoh Y, Oyake T, Hayashi N, Satoh K, Hatayama I, et al: An Nrf2/small Maf heterodimer mediates the induction of phase II detoxifying enzyme genes through antioxidant response elements. Biochem Biophys Res Commun 236: 313-322, 1997.

19. Dhakshinamoorthy S, Jain AK, Bloom DA and Jaiswal AK: Bach1 competes with Nrf2 leading to negative regulation of the antioxidant response element (ARE)-mediated NAD(P)H: Quinone oxidoreductase 1 gene expression and induction in response to antioxidants. J Biol Chem 280: 16891-16900, 2005.

20. Reichard JF, Motz GT and Puga A: Heme oxygenase-1 induction by NRF2 requires inactivation of the transcriptional repressor BACH1. Nucleic Acids Res 35: 7074-7086, 2007.

21. Medina MV, Sapochnik D, Garcia Solá M and Coso O: Regulation of the expression of heme oxygenase-1: Signal transduction, gene promoter activation, and beyond. Antioxid Redox Signal 32: 1033-1044, 2020.

22. Alam J and Cook JL: How many transcription factors does it take to turn on the heme oxygenase-1 gene? Am J Respir Cell Mol Biol 36: 166-174, 2007.

23. Dawn B and Bolli R: HO-1 induction by HIF-1: A new mechanism for delayed cardioprotection? Am J Physiol Heart Circ Physiol 289: H522-H524, 2005.

24. Li X, Yu J, Gong L, Zhang Y, Dong S, Shi J, Li C, Li Y, Zhang Y and $\mathrm{Li} \mathrm{H}$ : Heme oxygenase-1(HO-1) regulates Golgi stress and attenuates endotoxin-induced acute lung injury through hypoxia inducible factor- $1 \alpha(\mathrm{HIF}-1 \alpha) / \mathrm{HO}-1$ signaling pathway. Free Radic Biol Med 165: 243-253, 2021.

25. Tong Y, Kai J, Wang S, Yu Y, Xie S, Zheng H, Wang Y, Liu Y, Zhu K, Guan X, et al: VHL regulates the sensitivity of clear cell renal cell carcinoma to SIRT4-mediated metabolic stress via HIF-1 $\alpha / \mathrm{HO}-1$ pathway. Cell Death Dis 12: 621, 2021.

26. He C, Zhang W, Li S, Ruan W, Xu J and Xiao F: Edaravone improves septic cardiac function by inducing an HIF-1 $\alpha / \mathrm{HO}-1$ pathway. Oxid Med Cell Longev 2018: 5216383, 2018.

27. Lee PJ, Jiang B-H, Chin BY, Iyer NV, Alam J, Semenza GL and Choi AK: Hypoxia-inducible factor-1 mediates transcriptional activation of the heme oxygenase-1 gene in response to hypoxia. J Biol Chem 272: 5375-5381, 1997.

28. Tanos T, Marinissen MJ, Leskow FC, Hochbaum D, Martinetto H, Gutkind JS and Coso OA: Phosphorylation of c-Fos by members of the p38 MAPK family. Role in the AP-1 response to UV light. J Biol Chem 280: 18842-18852, 2005.

29. Monje P, Marinissen MJ and Gutkind JS: Phosphorylation of the carboxyl-terminal transactivation domain of c-Fos by extracellular signal-regulated kinase mediates the transcriptional activation of AP-1 and cellular transformation induced by platelet-derived growth factor. Mol Cell Biol 23: 7030-7043, 2003.

30. McBride K and Nemer M: The C-terminal domain of c-fos is required for activation of an AP-1 site specific for jun-fos heterodimers. Mol Cell Biol 18: 5073-5081, 1998.

31. Yeh CH, Chen TP, Wang YC, Lin YM and Lin PJ: HO-1 activation can attenuate cardiomyocytic apoptosis via inhibition of NF-kappaB and AP-1 translocation following cardiac global ischemia and reperfusion. J Surg Res 155: 147-156, 2009.

32. Lee PJ, Camhi SL, Chin BY, Alam J and Choi AM: AP-1 and STAT mediate hyperoxia-induced gene transcription of heme oxygenase-1. Am J Physiol Lung Cell Mol Physiol 279: L175-L182, 2000. 
33. Paine A, Eiz-Vesper B, Blasczyk R and Immenschuh S: Signaling to heme oxygenase- 1 and its anti-inflammatory therapeutic potential. Biochem Pharmacol 80: 1895-1903, 2010.

34. Campbell NK, Fitzgerald HK and Dunne A: Regulation of inflammation by the antioxidant haem oxygenase 1 . Nat Rev Immunol 21: 411-425, 2021.

35. Merecz-Sadowska A, Sitarek P, Kucharska E, Kowalczyk T, Zajdel K, Cegliński T and Zajdel R: Antioxidant properties of plant-derived phenolic compounds and their effect on skin fibroblast cells. Antioxidants (Basel) 10: 726, 2021.

36. Yarmohammadi F, Hayes AW and Karimi G: Natural compounds against cytotoxic drug-induced cardiotoxicity: A review on the involvement of PI3K/Akt signaling pathway. J Biochem Mol Toxicol 35: e22683, 2021

37. Zhou Y, Jiang Z, Lu H, Xu Z, Tong R, Shi J and Jia G: Recent advances of natural polyphenols activators for Keap1-Nrf2 signaling pathway. Chem Biodivers 16: e1900400, 2019.

38. Zhang H, Liu YY, Jiang Q, Li KR, Zhao YX, Cao C and Yao J: Salvianolic acid A protects RPE cells against oxidative stress through activation of Nrf2/HO-1 signaling. Free Radic Biol Med 69: 219-228, 2014.

39. Zhang HF, Wang JH, Wang YL, Gao C, Gu YT, Huang J, Wang JH and Zhang Z: Salvianolic acid A protects the kidney against oxidative stress by activating the Akt/GSK-3 $\beta / \mathrm{Nrf} 2$ signaling pathway and inhibiting the NF- $\mathrm{KB}$ signaling pathway in $5 / 6$ nephrectomized rats. Oxid Med Cell Longev 2019: 2853534, 2019.

40. Gu X, Zheng C, Zheng Q, Chen S, Li W, Shang Z and Zhang H: Salvianolic acid A attenuates early brain injury after subarachnoid hemorrhage in rats by regulating ERK/P38/Nrf2 signaling. Am J Transl Res 9: 5643-5652, 2017.

41. Sun GY, Chen Z, Jasmer KJ, Chuang DY, Gu Z, Hannink M and Simonyi A: Quercetin attenuates inflammatory responses in BV-2 microglial cells: Role of MAPKs on the Nrf2 pathway and induction of heme oxygenase-1. PLoS One 10: e0141509, 2015.

42. Yao P, Nussler A, Liu L, Hao L, Song F, Schirmeier A and Nussler N: Quercetin protects human hepatocytes from ethanol-derived oxidative stress by inducing heme oxygenase-1 via the MAPK/Nrf2 pathways. J Hepatol 47: 253-261, 2007.

43. Campbell NK, Fitzgerald HK, Fletcher JM and Dunne A Plant-derived polyphenols modulate human dendritic cell metabolism and immune function via AMPK-dependent induction of heme oxygenase-1. Front Immunol 10: 345, 2019.

44. Kosuru R, Kandula V, Rai U, Prakash S, Xia Z and Singh S: Pterostilbene decreases cardiac oxidative stress and inflammation via activation of AMPK/Nrf2/HO-1 pathway in fructose-fed diabetic rats. Cardiovasc Drugs Ther 32: 147-163, 2018.

45. Nakasone R, Ashina M, Abe S, Tanimura K, Van Rostenberghe H and Fujioka K: The role of heme oxygenase-1 promoter polymorphisms in perinatal disease. Int J Environ Res Public Health 18: 3520,2021 .

46. Öllinger R and Pratschke J: Role of heme oxygenase-1 in transplantation. Transpl Int 23: 1071-1081, 2010.

47. Schulz S, Chisholm KM, Zhao H, Kalish F, Yang Y, Wong RJ and Stevenson DK: Heme oxygenase-1 confers protection and alters T-cell populations in a mouse model of neonatal intestinal inflammation. Pediatr Res 77: 640-648, 2015.

48. Gill AJ, Garza R, Ambegaokar SS, Gelman BB and Kolson DL: Heme oxygenase-1 promoter region (GT)n polymorphism associates with increased neuroimmune activation and risk for encephalitis in HIV infection. J Neuroinflammation 15: 70, 2018.

49. Kaplan M, Wong RJ and Stevenson DK: Heme oxygenase-1 promoter polymorphisms: Do they modulate neonatal hyperbilirubinemia? J Perinatol 37: 901-905, 2017.

50. Garza R, Gill AJ, Bastien BL, Garcia-Mesa Y, Gruenewald AL, Gelman BB, Tsima B, Gross R, Letendre SL and Kolson DL: Heme oxygenase-1 promoter (GT)n polymorphism associates with HIV neurocognitive impairment. Neurol Neuroimmunol Neuroinflamm 7: e710, 2020.

51. Chen YH, Lin SJ, Lin MW, Tsai HL, Kuo SS, Chen JW, Charng MJ, Wu TC, Chen LC, Ding YA, et al: Microsatellite polymorphism in promoter of heme oxygenase-1 gene is associated with susceptibility to coronary artery disease in type 2 diabetic patients. Hum Genet 111: 1-8, 2002

52. Yamada N, Yamaya M, Okinaga S, Nakayama K, Sekizawa K, Shibahara S and Sasaki H: Microsatellite polymorphism in the heme oxygenase-1 gene promoter is associated with susceptibility to emphysema. Am J Hum Genet 66: 187-195, 2000.

53. Espinoza JA, González PA and Kalergis AM: Modulation of antiviral immunity by heme oxygenase-1. Am J Pathol 187: 487-493, 2017.
54. Zhou Y, Wang SN, Li H, Zha W, Peng Q, Li S, Chen Y and Jin L: Quantitative trait analysis of polymorphisms in two bilirubin metabolism enzymes to physiologic bilirubin levels in Chinese newborns. J Pediatr 165: 1154-1160.e1, 2014.

55. Wenzel P, Rossmann H, Müller C, Kossmann S, Oelze M, Schulz A, Arnold N, Simsek C, Lagrange J, Klemz R, et al: Heme oxygenase-1 suppresses a pro-inflammatory phenotype in monocytes and determines endothelial function and arterial hypertension in mice and humans. Eur Heart J 36: 3437-3446, 2015.

56. Pechlaner R, Willeit P, Summerer M, Santer P, Egger G, Kronenberg F, Demetz E, Weiss G, Tsimikas S, Witztum JL, et al: Heme oxygenase-1 gene promoter microsatellite polymorphism is associated with progressive atherosclerosis and incident cardiovascular disease. Arterioscler Thromb Vasc Biol 35: 229-236, 2015.

57. Leaf DE, Body SC, Muehlschlegel JD, McMahon GM, Lichtner P, Collard CD, Shernan SK, Fox AA and Waikar SS: Length polymorphisms in heme oxygenase-1 and AKI after cardiac surgery. J Am Soc Nephrol 27: 3291-3297, 2016.

58. Zhang MM, Zheng YY, Gao Y, Zhang JZ, Liu F, Yang YN, Li XM, Ma YT and Xie X: Heme oxygenase-1 gene promoter polymorphisms are associated with coronary heart disease and restenosis after percutaneous coronary intervention: A meta-analysis. Oncotarget 7: 83437-83450, 2016.

59. Ono K, Mannami T and Iwai N: Association of a promoter variant of the haeme oxygenase- 1 gene with hypertension in women. J Hypertens 21: 1497-1503, 2003.

60. Ellakany WI, Mahmoud MoheyEldin K, Invernizzi P, Mahmoud ElKady A, Eldin Fathy Abou Elkheir H, Abdel Haleem Abo Elwafa R and Ellakany A: Study of the influence of heme oxygenase 1 gene single nucleotide polymorphism (rs2071746) on esophageal varices among patients with cirrhosis. Eur J Gastroenterol Hepatol 30: 888-892, 2018.

61. Ono K, Goto Y, Takagi S, Baba S, Tago N, Nonogi H and Iwai N: A promoter variant of the heme oxygenase-1 gene may reduce the incidence of ischemic heart disease in Japanese. Atherosclerosis 173: 313-319, 2004.

62. Buis CI, van der Steege G, Visser DS, Nolte IM, Hepkema BG, Nijsten M, Slooff MJ and Porte RJ: Heme oxygenase-1 genotype of the donor is associated with graft survival after liver transplantation. Am J Transplant 8: 377-385, 2008.

63. Rich A, Nordheim A and Wang AH: The chemistry and biology of left-handed Z-DNA. Annu Rev Biochem 53: 791-846, 1984.

64. Naylor LH and Clark EM: d(TG)n.d(CA)n sequences upstream of the rat prolactin gene form Z-DNA and inhibit gene transcription. Nucleic Acids Res 18: 1595-1601, 1990.

65. Kramer M, Sponholz C, Slaba M, Wissuwa B, Claus RA, Menzel U, Huse K, Platzer M and Bauer M: Alternative 5' untranslated regions are involved in expression regulation of human heme oxygenase-1. PLoS One 8: e77224, 2013

66. Doberer D, Haschemi A, Andreas M, Zapf TC, Clive B, Jeitler M, Heinzl H, Wagner O, Wolzt M and Bilban M: Haem arginate infusion stimulates haem oxygenase-1 expression in healthy subjects. Br J Pharmacol 161: 1751-1762, 2010.

67. Hong CC, Ambrosone CB, Ahn J, Choi JY, McCullough ML, Stevens VL, Rodriguez C, Thun MJ and Calle EE: Genetic variability in iron-related oxidative stress pathways (Nrf2, NQ01, NOS3, and HO-1), iron intake, and risk of postmenopausal breast cancer. Cancer Epidemiol Biomarkers Prev 16: 1784-1794, 2007.

68. Abraham NG and Kappas A: Pharmacological and clinical aspects of heme oxygenase. Pharmacol Rev 60: 79-127, 2008.

69. Liang KW, Lee WJ, Lee WL, Wu JP, Lee IT, Wang JS and Sheu WH: Subjects with coronary artery disease and reduced ejection fraction have longer (GT)n repeats in the heme-oxygenase 1 gene promoter. Heart Vessels 36: 615-620, 2021.

70. Wu MM, Chiou HY, Chen CL, Hsu LI, Lien LM, Wang CH, Hsieh YC, Wang YH, Hsueh YM, Lee TC, et al: Association of heme oxygenase-1 GT-repeat polymorphism with blood pressure phenotypes and its relevance to future cardiovascular mortality risk: An observation based on arsenic-exposed individuals. Atherosclerosis 219: 704-708, 2011

71. Ross R: Atherosclerosis-an inflammatory disease. N Engl J Med 340: 115-126, 1999.

72. Duckers HJ, Boehm M, True AL, Yet SF, San H, Park JL, Clinton Webb R, Lee ME, Nabel GJ and Nabel EG: Heme oxygenase-1 protects against vascular constriction and proliferation. Nat Med 7: 693-698, 2001.

73. Ishikawa K, Sugawara D, Wang XP, Suzuki K, Itabe H, Maruyama Y and Lusis AJ: Heme oxygenase-1 inhibits atherosclerotic lesion formation in ldl-receptor knockout mice. Circ Res 88: 506-512, 2001. 
74. Tulis DA, Durante W, Peyton KJ, Evans AJ and Schafer AI: Heme oxygenase-1 attenuates vascular remodeling following balloon injury in rat carotid arteries. Atherosclerosis 155: 113-122, 2001.

75. Lindenblatt N, Bordel R, Schareck W, Menger MD and Vollmar B: Vascular heme oxygenase-1 induction suppresses microvascular thrombus formation in vivo. Arterioscler Thromb Vasc Biol 24: 601-606, 2004.

76. Liang KW, Lee WJ, Lee IT, Lee WL, Wang JS, Wu JP and Sheu WHH: Subjects with microvascular angina have longer GT repeats polymorphism in the haem oxygenase-1 gene promoter. Biomarkers 25: 144-148, 2020.

77. Raval CM and Lee PJ: Heme oxygenase-1 in lung disease. Curr Drug Targets 11: 1532-1540, 2010.

78. Du Y, Zhang H, Xu Y, Ding Y, Chen X, Mei Z, Ding H and Jie Z: Association among genetic polymorphisms of GSTP1, HO-1, and SOD-3 and chronic obstructive pulmonary disease susceptibility. Int J Chron Obstruct Pulmon Dis 14: 2081-2088, 2019.

79. Zhou H, Ying X, Liu Y, Ye S, Yan J and Li Y: Genetic polymorphism of heme oxygenase 1 promoter in the occurrence and severity of chronic obstructive pulmonary disease: A meta-analysis. J Cell Mol Med 21: 894-903, 2017.

80. Fischer BM, Pavlisko E and Voynow JA: Pathogenic triad in COPD: Oxidative stress, protease-antiprotease imbalance, and inflammation. Int J Chron Obstruct Pulmon Dis 6: 413-421, 2011.

81. Zhang JQ, Zhang JQ, Fang LZ, Liu L, Fu WP and Dai LM: Effect of oral $\mathrm{N}$-acetylcysteine on COPD patients with microsatellite polymorphism in the heme oxygenase-1 gene promoter. Drug Des Devel Ther 9: 6379-6387, 2015.

82. Zhang ZY, Guan J, Li H, Zhou ZQ and Zhou GW: Heme oxygenase-1 promoter polymorphism protects liver allograft. Indian J Surg 78: 14-19, 2016.

83. Soares M, Lin Y, Anrather J, Csizmadia E, Takigami K, Sato K, Grey ST, Colvin RB, Choi AM, Poss KD and Bach FH: Expression of heme oxygenase-1 can determine cardiac xenograft survival. Nat Med 4: 1073-1077, 1998.

84. Katori M, Buelow R, Ke B, Ma J, Coito AJ, Iyer S, Southard D, Busuttil RW and Kupiec-Weglinski JW: Heme oxygenase-1 overexpression protects rat hearts from cold ischemia/reperfusion injury via an antiapoptotic pathway. Transplantation 73: 287-292, 2002.

85. Ozaki KS, Marques GM, Nogueira E, Feitoza RQ, Cenedeze MA, Franco MF, Mazzali M, Soares MP, Pacheco-Silva A and Câmara NO: Improved renal function after kidney transplantation is associated with heme oxygenase-1 polymorphism. Clin Transplant 22: 609-616, 2008.

86. Nisula S, Kaukonen KM, Vaara ST, Korhonen AM, Poukkanen M, Karlsson S, Haapio M, Inkinen O, Parviainen I, Suojaranta-Ylinen $\mathrm{R}$, et al: Incidence, risk factors and 90-day mortality of patients with acute kidney injury in Finnish intensive care units: The FINNAKI study. Intensive Care Med 39: 420-428, 2013

87. Vilander LM, Vaara ST, Donner KM, Lakkisto P, Kaunisto MA and Pettilä V; FINNAKI Study Group: Heme oxygenase-1 repeat polymorphism in septic acute kidney injury. PLoS One 14: e0217291, 2019.

88. Vashist YK, Uzungolu G, Kutup A, Gebauer F, Koenig A, Deutsch L, Zehler O, Busch P, Kalinin V, Izbicki JR and Yekebas EF: Heme oxygenase-1 germ line GTn promoter polymorphism is an independent prognosticator of tumor recurrence and survival in pancreatic cancer. J Surg Oncol 104: 305-311, 2011

89. Okamoto I, Krögler J, Endler G, Kaufmann S, Mustafa S, Exner M, Mannhalter C, Wagner O and Pehamberger $\mathrm{H}$ : A microsatellite polymorphism in the heme oxygenase-1 gene promoter is associated with risk for melanoma. Int J Cancer 119: $1312-1315,2006$

90. Berberat PO, Dambrauskas Z, Gulbinas A, Giese T, Giese N, Künzli B, Autschbach F, Meuer S, Büchler MW and Friess H: Inhibition of heme oxygenase-1 increases responsiveness of pancreatic cancer cells to anticancer treatment. Clin Cancer Res 11: 3790-3798, 2005

91. Sunamura M, Duda DG, Ghattas MH, Lozonschi L, Motoi F, Yamauchi J, Matsuno S, Shibahara S and Abraham NG: Heme oxygenase-1 accelerates tumor angiogenesis of human pancreatic cancer. Angiogenesis 6: 15-24, 2003.

92. Bukowska-Strakova K, Włodek J, Pitera E, Kozakowska M, Konturek-Cieśla A, Cieśla M, Gońka M, Nowak W, Wieczorek A, Pawińska-Wąsikowska K, et al: Role of HMOX1 promoter genetic variants in chemoresistance and chemotherapy induced neutropenia in children with acute lymphoblastic leukemia. Int J Mol Sci 22: 988, 2021.
93. Tang D, Tang WJ, Shi XL, Li WP, Zhou H, Lu LM and Tao L: Association of the microsatellite (GT)n repeat polymorphisms of the HO-1 gene promoter and corresponding serum levels with the risk of laryngeal squamous cell carcinoma. Acta Otolaryngol 136 806-811, 2016.

94. Zhang L, Song FF, Huang YB, Zheng H, Song FJ and Chen KX Association between the (GT)n polymorphism of the HO-1 gene promoter region and cancer risk: A meta-analysis. Asian Pac J Cancer Prev 15: 4617-4622, 2014

95. Hu JL, Li ZY, Liu W, Zhang RG, Li GL, Wang T, Ren JH and Wu G: Polymorphism in heme oxygenase-1 (HO-1) promoter and alcohol are related to the risk of esophageal squamous cell carcinoma on Chinese males. Neoplasma 57: 86-92, 2010.

96. Lo SS, Lin SC, Wu CW, Chen JH, Yeh WI, Chung MY and Lui WY: Heme oxygenase-1 gene promoter polymorphism is associated with risk of gastric adenocarcinoma and lymphovascular tumor invasion. Ann Surg Oncol 14: 2250-2256, 2007.

97. Sawa T, Mounawar M, Tatemichi M, Gilibert I, Katoh T and Ohshima H: Increased risk of gastric cancer in Japanese subjects is associated with microsatellite polymorphisms in the heme oxygenase- 1 and the inducible nitric oxide synthase gene promoters. Cancer Lett 269: 78-84, 2008.

98. Kikuchi A, Yamaya M, Suzuki S, Yasuda H,Kubo H, Nakayama K, Handa M, Sasaki T, Shibahara S, Sekizawa K and Sasaki H Association of susceptibility to the development of lung adenocarcinoma with the heme oxygenase-1 gene promoter polymorphism. Hum Genet 116: 354-360, 2005

99. Jirásková A, Novotný J, Novotný L, Vodicka P, Pardini B, Naccarati A, Schwertner HA, Hubácek JA, Puncochárová L, Šmerhovský Z and Vítek L: Association of serum bilirubin and promoter variations in HMOX1 and UGT1A1 genes with sporadic colorectal cancer. Int J Cancer 131: 1549-1555, 2012.

100. Podkalicka P, Mucha O, Józkowicz A, Dulak J and Łoboda A Heme oxygenase inhibition in cancers: Possible tools and targets. Contemp Oncol (Pozn) 22: 32-23, 2018.

101. Kah J, Volz T, Lütgehetmann M, Groth A, Lohse AW, Tiegs G, Sass G and Dandri M: Haem oxygenase-1 polymorphisms can affect $\mathrm{HCV}$ replication and treatment responses with different efficacy in humanized mice. Liver Int 37: 1128-1137, 2017.

102. Singh D, Wasan H and Reeta KH: Heme oxygenase-1 modulation: A potential therapeutic target for COVID-19 and associated complications. Free Radic Biol Med 161: 263-271, 2020.

103. Zhou JF, Luo JY, Zhu WB, Yang CY, Zeng YL and Qiu XL: Association between genetic polymorphism of heme oxygenase 1 promoter and neonatal hyperbilirubinemia: A meta-analysis. J Matern Fetal Neonatal Med 34: 12-23, 2021.

104. Wagener FA, Toonen EJ, Wigman L, Fransen J, Creemers MC, Radstake TR, Coenen MJ, Barrera P, van Riel PL and Russel FG: HMOX1 promoter polymorphism modulates the relationship between disease activity and joint damage in rheumatoid arthritis. Arthritis Rheum 58: 3388-3393, 2008

105. Gulla A, Gulbinas A, Dambrauskas Z and Strupas K: Heme oxygenase-1 polymorphism is associated with the development of necrotic acute pancreatitis via vascular cell adhesion molecule-1 and the E-selectin expression regulation pathway. Pancreas 48: 787-791, 2019.

106. Lee EY, Lee YH, Kim SH, Chung KS, Kwon O, Kim BS, Nam CM, Park CS, Lee BW, Kang ES, et al: Association between heme oxygenase-1 promoter polymorphisms and the development of albuminuria in type 2 diabetes: A case-control study. Medicine (Baltimore) 94: e1825, 2015

107. Holweg CT, Balk AH, Uitterlinden AG, Niesters HG, Maat LP, Weimar W and Baan CC: Functional heme oxygenase-1 promoter polymorphism in relation to heart failure and cardiac transplantation. J Heart Lung Transplant 24: 493-497, 2005.

108. Foresti R, Bains SK, Pitchumony TS, de Castro Brás LE, Drago F, Dubois-Randé JL, Bucolo C and Motterlini R: Small molecule activators of the Nrf2-HO-1 antioxidant axis modulate heme metabolism and inflammation in BV2 microglia cells. Pharmacol Res 76: 132-148, 2013

109. Funes SC, Rios M, Fernández-Fierro A, Covián C, Bueno SM, Riedel CA, Mackern-Oberti JP and Kalergis AM: Naturally derived heme-oxygenase 1 inducers and their therapeutic application to immune-mediated diseases. Front Immunol 11: 1467, 2020.

This work is licensed under a Creative Commons Attribution-NonCommercial-NoDerivatives 4.0 International (CC BY-NC-ND 4.0) License. 